\title{
RESEARCH
}

\section{A novel information sharing framework for people living with type-2 diabetes in the context of a group education program}

\author{
Atae Rezaei Aghdam ${ }^{1}$ Jason Watson ${ }^{1}$, Shah Jahan Miah ${ }^{2^{*}}$ (D) and Cynthia Cliff ${ }^{3}$
}

\begin{abstract}
Purpose: Online health communities (OHCs) offer opportunities for people with type-2 diabetes to share information and experiences for self improvement. This study is to introduce a novel framework for identifying the potential of online diabetes communities' practices and outcomes in empowering people living with diabetes.

Method: : Using a qualitative tradition, we conducted semi-structured interviews with 15 members of these communities, attempting to answer research question: how an online framework for diabetes community can be outlined for empowering patients in their self-management in the context of DGEP. We also analysed 2312 threads shared in the three popular type-2 diabetes Reddit communities (r/diabetes, r/diabetes_t2, and r/type2diabetes) comprising more than 60,000 members.?
\end{abstract}

Results: Using thematic analysis, the study identifies three salient themes: (a) Leverage digital health technologies to ubiquitous access, share and integrate resources, (b) Community encouragement in self-care and self-monitoring, and (c) Improve mental well-being by experiencing commonality. Statistically, on average $87 \%$ of the participants contended that they would benefit the OHC framework for keeping them interconnected to the program. Furthermore, expert interviews with the healthcare team have been carried out for evaluating the usability and efficiency of the framework.

Conclusions: The proposed information-sharing framework promotes patients' self-management of diabetes, revealing that patient participation in diabetes $\mathrm{OHC}$ leads to empowering self-management of their diabetes and in turns shedding some light on how healthcare organizations can improve patients' information behaviour through OHC provisions. This qualitative study suggested that the proposed novel framework is perceived as a useful platform to empower diabetic patients in their self-management, extending value of physical group activities.

Keywords: Diabetes self-management, Online health communities, Patient empowerment, Type-2 diabetes, Information sharing

\section{Introduction}

Frequently, the management of chronic disease involves a fundamental change in everyday behaviours with most of the burden falling outside of supervised healthcare environments [1]. A type-2 diabetes diagnosis, for example, requires significant lifestyle changes including ongoing

\footnotetext{
*Correspondence: shah.miah@newcastle.edu.au

${ }^{2}$ Newcastle Business School, The University of Newcastle, Newcastle City

Campus, Newcastle, Australia

Full list of author information is available at the end of the article
}

self-management and self-awareness [2]. According to the International Diabetes Federation (IDF), by 2040 one adult in ten will have diabetes (a predicted total of 642 million patients) [3]. The decisions that they make daily have a profound influence on their health. Effective self-management is one of the most significant determinants of positive health outcomes for people with type-2 diabetes [4]. Self-management requires significant information effort, including seeking, managing, and using health-related best care practice based information [5]. Online health communities $(\mathrm{OHC})$ can facilitate this 
activity [6]. They diminish geographical barriers and enable stakeholders such as patients, physicians, caregivers, and healthcare organizations to access and share health information. They are also a source of social, and emotional support $[7,8]$ and value co-creation. The exchange of health information and experiences in OHCs supports and empowers patients with diabetes to engage in selfmanagement [9]. Since more than $95 \%$ of diabetes care is undertaken by patients themselves outside of medical centres or at home $[10,11]$ the availability of affordable and easily assessable 24/7 OHCs facilitates and promotes personal self-management [12]. Because people tend to trust others within their network groups, who are similar to themselves rather than organizations, businesses, or government figures and the media [13], the content shared by peers in $\mathrm{OHCs}$ has potential to encourage community members to engage in health-related online activities [14]. Patients play an active role rather than act as a passive recipient of healthcare services [14]. This active patient participation leads to co-created value [15]. In this healthcare context, value co-creation refers to "activities centered around the individual patients or in collaboration with numbers of the service delivery network including the patient, family, friends, other patients, health professionals and the outside community" [16]. Prior research has focused primarily on ways of facilitating behavior change to engage and motivate diabetes self-management.

The remaining sections of this paper are organized as follows. The subsequent section includes reviews of related works drawn from the diabetes education literature and the literature addressing online health communities. The "Materials and methods" section explains the methods of data collection and data analysis leading to development of the proposed framework. Our proposed framework is presented in "Results and discussion" section. And finally, the "Conclusions" section points to potential avenues for further development.

\section{Related works}

Previous studies have reinforced new technological development for improving provisions of diabetics management. Various existing studies have described innovations in this problem domain. For example, AlMarshedi et al. [17] investigated behavioural change among diabetic patients in order to develop a conceptual model employing gamification. The main objective of AlMarshedi's work was to promote better self-management of diabetes through user engagement to drive behavioural change. Likewise, Fisher et al. [18] proposed a technical framework for encouraging and supporting positive behaviour change in diabetes by defining a three-step framework for organizing specific clinical processes. Diabetes education has also been a focus of many prior studies. Diabetes education is a specific intervention that supports diabetes self-management [19]. A systematic review and meta-analysis indicate that diabetes education improves clinical, lifestyle, and psychological outcomes for type-2 diabetic patients compared to usual care [20]. Synthesis of the current literature indicates, however, that the potential for a new OHC framework to improve the clinical, lifestyle and psychological outcomes for people with type-2 diabetes has not been investigated for fully functional knowledge development in this domain. Relevant literature also indicate that a new $\mathrm{OHC}$ framework that: includes opportunities for individuals to exchange and brainstorm new ideas for diabetes self-management; functions as a bridge between people with type- 2 diabetes, and between people with type- 2 diabetes and healthcare professionals; and provides online discussion platforms for information sharing, would be paramount research in the e-health discipline [21].

The management of diabetes requires a patient-centred approach in place [22]. Given the fact that most successful diabetes self-management group activities and classes that have been thoroughly evaluated to date are based on empowerment theory [23], our study applied this theory in the context of the online value co-creation, having an anticipation to extend the value of the empowerment theory in online health environments. This would increase the opportunity for patients to engage in value co-creation activities during their health journey, ultimately, empowering them in their self-management of diabetes. The theory claims that actions, activities or structures may be empowering and the outcome of such processes leads to being empowered [24]. As such in our understanding in relation to the proposed framework, which is patient-centred, emphasizing the empowering diabetic patients in self-management of their diabetes. According to the empowerment theory, people need opportunities to become active in community decision-making to improve their quality of lives, as such we propose an affordable and easily accessible 24/7 digital health platform to facilitate the process of self-management through informational, social, and emotional support. Therefore, the community can be empowered because the community members activities, which lead to improving their collective quality of life [24]. Therefore, this study develops a new framework to address diabetes-related needs and challenges including; informational, emotional, social, psychological and co-creational. Accordingly, the overarching research question is: How can an online diabetes community framework be outlined for empowering patients in their self-management in the context of Diabetes Group Education Program (DGEP)? 
Patient education is one of the key methods for selfmanagement of chronic disease in order to improve health outcomes $[25,26]$. A group-based educational program has become a popular practice, specifically to enhance the self-management skills of patients. Prior research mostly focused on the behaviour change of diabetes to engage and motivate diabetic people in their self-management of diabetes. Ramaswamy and Ozcan [27] proposed a fresh novel interactional value creation framework, emphasizing the interactions among actors. In their frameworks, stakeholders may go beyond the roles of two or more human actors coming together in associative activities. It involves a multiplicity of interactive system-environment among stakeholders and entities such as online platforms [27]. Accordingly, the framework establishes a systematic way of moving from the interactions of actors to generate value through interactive platforms [27]. Because of the nature of the diabetes group education program, which is focused on the interaction among patients prior to join, during and after the program, the interactional co-creation framework would be an ideal bedrock to facilitate the process of value co-creation for empowering patients in their self-management. In this study, we have drawn the context to identify the online value co-creation behaviour, practices, and outcomes among users of online diabetes communities on the Reddit to empower diabetic patients, who are participating in a face-to-face DGEP.

\section{Materials and methods}

\section{0-Week Diabetes Group Education Program (DGEP)}

Research has demonstrated that participants in diabetes group-based education programs benefit from the social and emotional support of meeting and discussing their experience with others in the group [28]. The Queensland University of Technology (QUT) offers a partnership 10-Week face-to-face DGEP to patients who are newly diagnosed or living with the type-2 diabetes long term. Over the course of 10 weeks, the QUT DGEP aims to provide a quality lifestyle intervention empowering type-2 diabetic patients to better manage their symptoms. The outcome of this award-wining program are promising and all patients involved no longer needing to stay on the long waiting list of the hospitals. One of the most significant aims of this program is to keep patients connected to the program after discharged and while outside of the program. Participants from this program formed the study cohort for the development of the new OHC framework. The details of the QUT-DGEP program are presented in Appendix 1.

\section{Diabetes online communities on Reddit}

One of the popular online discussion forums for diabetes is "Reddit" [29]. Reddit is a social news aggregation and public discussion website. There are numerous healthrelated topics on this website, which make it a promising source of user's interactions for this research study. In fact, the interactions between users are mostly focused on the posts themselves and members will give the post all their attention. As such, Reddit is an ideal platform to investigate the interactions between users in this research study. In each community, there are a variety of threads and topics that users discuss them. Threads on Reddit can be categorized based on six different criteria such as; "Best", "Hot", "New", "Controversial, "Top", and "Rising". To ensure that relevant threads are not neglected, we considered all of these categories in the data collection process. Reddit allows researchers to mining data. Hence, we used the Python Reddit Application Programming Interface (API) Wrapper (PRAW) to collect the data. PRAW is a Python package that allows researchers to access, parse topics and subreddit, and extract the associated reply threads. The interactions between users are mostly focused on the posts themselves and members will give the post all their attention. Three popular diabetes communities ( $r$ /diabetes, $r /$ type2diabetes, and $r / d i a-$ betes_t2) comprise of more than 60,000 members were identified through keyword search including "diabetes", "type-2 diabetes", “T2DM", "diabetic", and "T2D”. From each topic, the title and the content (e.g., textual information) were extracted without the additional information of the authors. A total of 212 topics were collected from Reddit from October 2019 to May 2020. In total 2312 threads were collected for analysis.

\section{Interviews}

The second set of data was collected through semi-structured online interview with the members of the type-2 diabetes online communities on Reddit. For recruiting participants, the first author posted a topic in the identified three communities with the detailed information about the nature of the research and objectives, inviting volunteers to participate in an online interview via Skype or Zoom. Our inclusion criteria for selecting participants were (1) participants should type-2 diabetic patients, (2) participant should be a member of the diabetes communities for more than 2 months, (3) actively engage and contribute to the online discussions. In the interviews, participants were asked to share their experience regarding the following topics: their current level of engagement in OHCs, benefits and challenges of using OHCs, online support that they give and offer concerning their diabetes, and online value co-creation behaviours in diabetes 
online communities. Most of the interviewees were from the US and Australia. Data saturation was indicated after analysing 15 interviews by the overall thematic data replications. All of the interviews were recorded as audio files and transcribed verbatim. Each interview lasting on average 45 min was conducted in February and March 2020. Demographic information about the participants was anonymized to guarantee the confidentiality and privacy of participants' data.

\section{Proposed framework}

The terminology "value co-creation" have been popularized on the interactional nature of value through developing a co-creation framework in which resource integration happens in interactive platforms [27]. According to the findings, participating in OHCs should empower diabetes patients. Thus, another concept considered in the proposed framework is Customer-Dominant Logic (CDL), which is focused on the activities and experiences of customers. CDL suggests that customers control service situations and become increasingly empowered, in our case, health care consumers. This direction will most likely continue in the future [30]. Therefore, our proposed framework lies in these two novel concepts. The framework (Fig. 1) includes three main phases: (1) Pre-Service, (2) Service, and (3) PostService. In the first phase, patients, who are in the waiting list of the face-to-face DGEP program, can interact with peers, healthcare professionals ( $\mathrm{HCPs}$ ) and patients who completed the DGEP. These kinds of interactions in this stage assist patients to reduce their stress and increase their knowledge about their diabetes. In the second phase, when patients are in the DGEP program, the $\mathrm{OHC}$ plays a role as an online interactive platform that facilitates patient-to-patient and patient-to-HCP interaction. In fact, during the 10-week DGEP, patients share their experience and health-related stories with peers, emotionally support and encourage each other to reach their health-related goals both face-to-face and in the OHC. In the third phase, discharged patients share their advice and experiences of being in the program with others especially with pre-join patients. These activities assist patients to stay connected to the program and improve their self-management of care.

The study also evaluates the framework for its validity and utilities through expert interviews. A qualitative assessment of the framework flexibility was carried out through expert interviews conducted with HCPs and the DGEP program coordinators. Three health experts who are directly involved in the diabetes education program and have more than 3 years of management of experience in the health service field initially evaluated the framework. These health experts also verified the proposed framework in details and appropriate modification have been made respecting to their effective feedback (see Appendix 2). In addition, we conducted a focus group with the program coordinators and healthcare team of the DGEP. The participants were asked to come to consensus on particular phases of the framework (prior to join, during the program, and after discharge from the program). After conducting the focus group, some changes were made to the proposed framework. The focus group script was carefully analysed by the authors.

\section{Results and discussion}

In this study, we conducted the inductive thematic analysis following the six steps of coding proposed by Braun and Clarke [31] to identify the salient themes of the shared content on the Reddit diabetes communities and interviews transcript. We manually generated an initial list of codes using NVivo 12 qualitative analysis software. During the first step, we did a preliminary analysis of the contents of the Reddit communities and interviews' transcriptions. In the second step, we inductively generated an initial list of 116 nodes. In the third step, we re-focused the analysis process on broad themes, rather than codes, sorting the diverse codes into potential themes and sub-themes. In the fourth step, we reviewed and refined themes to make sure they followed a coherent pattern. During this phase, some sub-themes integrated due to the common content. In the fifth step, we refined and names the themes to reveal the story behind each theme. Furthermore, a detailed analysis was carried out to minimize the overlap between themes and ensure that they are aligned with the research question. Finally, in the last step of the thematic analysis, we provide a concise, coherent, and logical report to synthesize the themes as presented in the following sections. We repeated the same process for the data gathered from interviews, inductively generating 45 initial codes. During the coding process, the authors discussed and reviewed the nodes, themes, and sub-themes regularly and any disagreement or discrepancies were resolved regarding the reliability of the findings. Table 1 illustrates the themes, sub-themes and the quotations of value co-creation behaviour identified within the interactions of users.

The results of the thematic analysis for the interviews add extra insight into the findings of the content analysis of the Reddit diabetes communities. In terms of testing the trustworthiness of the findings, we employed percent agreement as our method of inter-coder reliability checking. Two scholars, experienced in qualitative research and thematic analysis, checked different parts from creating initial codes to naming the themes. Each of them independently analysed the entire data and during the first meeting, the per cent agreement was $75 \%$ and 


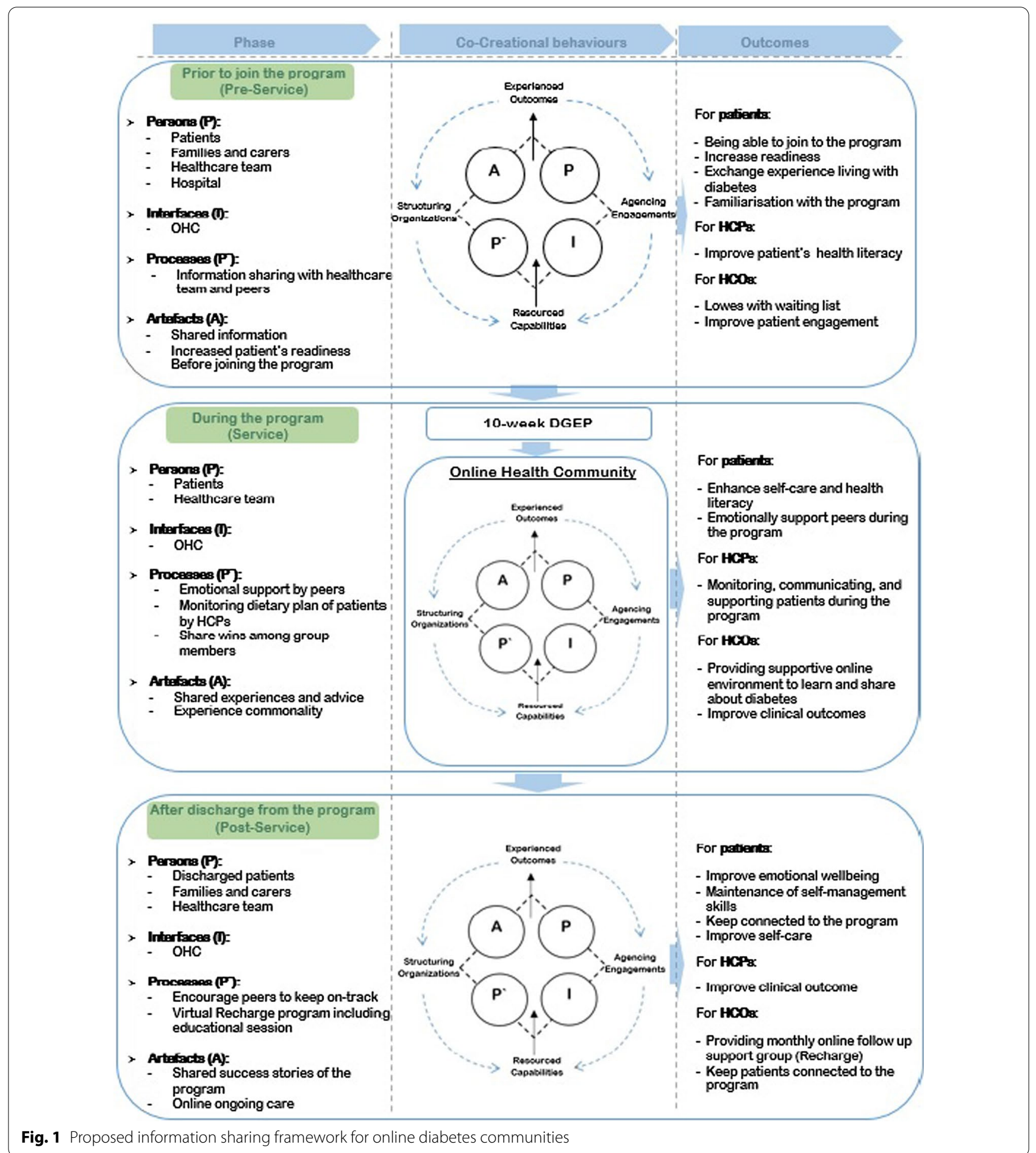

after the second meeting, discussing the essence of the themes, a consensus was achieved and the overall results were $100 \%$, making us confident about the reliability of our literature review.
Themes' explanations.

Through performing the thematic analysis, we identified three emergent themes; (1) Leverage digital health technology to ubiquitous access, share, and integrate resources, (2) Community Encouragement in Self-care 
Table 1 Summary of the thematic analysis findings

\begin{tabular}{|c|c|c|c|}
\hline Theme & Sub-themes & $\begin{array}{l}\text { Percentage of } \\
\text { supporting the } \\
\text { themes }\end{array}$ & Example quotations \\
\hline $\begin{array}{l}\text { (1) Leverage digital } \\
\text { health technolo- } \\
\text { gies to ubiquitous } \\
\text { access, share, and } \\
\text { integrate resources }\end{array}$ & $\begin{array}{l}\text { - Exchange life style- } \\
\text { related advice } \\
\text { - Experience sharing } \\
\text { - Brainstorm solu- } \\
\text { tions for daily } \\
\text { challenges }\end{array}$ & $\begin{array}{l}\cdot 89 \\
\cdot 92 \\
\cdot 84\end{array}$ & $\begin{array}{l}\text { Reddit User 1: "What can I do to control my blood sugar?" } \\
\text { Reddit Users 2: "You can also explore some treatment as described in this study (the link of } \\
\text { the paper)" } \\
\text { Reddit User 1: "Thanks, some helpful information in here" } \\
\text { Interviewee 5: "It's accessible and I think that's probably the number one value for me. It is } \\
\text { accessible 24/7" }\end{array}$ \\
\hline $\begin{array}{l}\text { (2) Community } \\
\text { encouragement in } \\
\text { self-care and self- } \\
\text { monitoring }\end{array}$ & $\begin{array}{l}\text { - Encouraging peers } \\
\text { in self-care and } \\
\text { monitoring } \\
\text { - Sharing supportive } \\
\text { phrases }\end{array}$ & $\begin{array}{r}\cdot 79 \\
\cdot 71\end{array}$ & $\begin{array}{l}\text { Reddit User: "I feel super motivated to bring down my diabetes" } \\
\text { Reddit User: "Find you passions in life and live them, whatever they maybe. } \\
\text { Interviewee 14: "I always try to encourage and congratulate people on their success, } \\
\text { progress, and transformation, because it's really important" }\end{array}$ \\
\hline $\begin{array}{l}\text { (3) Improve mental } \\
\text { well-being by } \\
\text { experiencing com- } \\
\text { monality }\end{array}$ & $\begin{array}{c}\text { - Reduce diabetes } \\
\text { stress and anxiety } \\
\text { - Share same situa- } \\
\text { tion and stories } \\
\text { - Feel less isolated }\end{array}$ & $\begin{array}{l}\cdot 83 \\
\cdot 84 \\
\cdot 83\end{array}$ & $\begin{array}{l}\text { Reddit User 1: "No medicine. No treatment. I am scared to death. Things are only going to } \\
\text { get worse from this point, is it? Please tell me. I don't think I can live with this depression". } \\
\text { Reddit User 2: "You certainly should not consider inevitable or inevitably progressive. } \\
\text { Worst-case scenario is you can stop it in its track. Best case scenario is you can reverse the } \\
\text { damage" } \\
\text { Reddit User 1: "Thank you so much for just telling me that there is a hope. I already feel } \\
\text { better (not physically but mentally)" } \\
\text { Interviewee 9: "Well, especially with the outbreak recently. It's a lot of support. A lot of } \\
\text { people are keeping each other on track; they're keeping each other sane" } \\
\text { Reddit User: "I would like to say I appreciate this community so much, truly makes you feel } \\
\text { less alone" } \\
\text { Interviewee 6: "So you know you're not alone so there's a lot of emotional, mental benefits } \\
\text { to it" }\end{array}$ \\
\hline
\end{tabular}

and Self-monitoring, and (3) Improve Mental Well-being by Experiencing Commonality. The following sections explain each theme.

\section{Leverage digital health technologies to ubiquitous access, share and integrate resources}

The vast majority of users in diabetes online communities emphasizes information sharing by peers through story, experiences, daily activities, and lifestyle-related advice (e.g., diet and exercise). From statistical point of view, $74 \%$ of the users in the Reddit diabetes communities shared their health-related information with others, however $26 \%$ are concerned about their privacy and prefer to not share their information on online platforms. $43 \%$ Shared their experiences and health and success stories managing their diabetes. In addition, 38\% shared their daily activities and lifestyle-related advice and stories in relation to manage their diabetes. These types of advice-giving and seeking are illustrative examples of value co-creation behaviors. In the value co-creation process, stakeholders such as organizations, patients or caregivers share, integrate and renew each other's resources [32]. Our analysis shows that people with type-2 diabetes mostly shared their experience, stories, and online resources (e.g., research articles, YouTube videos, and websites' URLs). Further, the analysis of the interviews demonstrates that $\mathrm{OHCs}$ are the major source of resource sharing and integration. Resource exchange is a mutual action taken by stakeholders in OHCs to access, share, and integrate resources [33]. For instance, members of the diabetes communities shared their up-to-date information and experience about using wearable devices [e.g., Continues Glucose Monitors (CGM), Dexcom and sports watches] for self-management their health condition and reducing the burden of living with diabetes to improve quality of life. Digital health technologies have the potential to extend the value of the face-to-face diabetes group education program. In this regard, $\mathrm{OHCs}$ can facilitate resource exchange among stakeholder by providing $24 / 7$ ubiquitous and mobile access to health data. In addition, virtual brainstorming is one of the most significant benefits of $\mathrm{OHCs}$ for diabetic patients. It provides an opportunity for community members to contribute new ideas to address diabetic daily challenges such as carrying medical equipment, diabetic's workplace problems, and sleep problems.

\section{Community encouragement in self-care and self-monitoring}

In the Reddit diabetes communities, many users encourage peers in their self-management of diabetes. Patients also reported that sharing data such as blood glucose and weight makes them feel empowered and motivated. Members of these communities' support each other in 
coping with social and emotional barriers, staying motivated to reach their goals, and encourage better self-care habits without fear of judgement or stigma. Supportive post and threads in the Reddit community provide encouragement and empathy among members as well as providing benefits for those who seek emotional support. We identified several supportive phrases in diabetes online communities, encouraging peers to keep on-track and providing support for them. For instance, Supportive phrases such as "Choose to do better and don't beat yourself up when you fall. Just pick yourself up and keep going moving forward" keep other members of the community committee, encouraging them to keep on-track. Receiving support and encouragement from other members of the community empower patients in their self-management of diabetes. Due to the nature of the DGEP, which is a group-based educational program, the community encouragement and emotional support play an indispensable role in achieving the program goals and improving the quality of life for patients reducing their stress before and during the program.

\section{Improve mental well-being by experiencing commonality}

Psychological issues are one of the biggest challenges influencing the quality of life of people living with type-2 diabetes [34]. This study found that people with diabetes mostly share mental health challenges such as anxiety, depression, mood swings, and stress in OHCs. Users offer tips and techniques to tackle these issues. This was identified in many threads posted by the members of the communities when they integrated their resources (ideas) to come up with the new solutions. Given that type-2 diabetic patients have a twofold greater risk of depression [34], we identified the potential that participation in OHCs offers for tackling psychological issues. The experience of commonality provides opportunities for members to feel that they are not alone. OHCs empower patients to actively engage in sharing commonalities $24 / 7$ especially in times of fear, isolation, and uncertainty. At this point in time, people living with diabetes need to strengthen their sense of community by connecting and supporting each other in the OHCs. For instance, in the current tough situation of a global outbreak of COVID19 , OHCs are ideal places for members to tackle psychological distress. The experience of commonality is associated with positive mental wellbeing. Our Findings revealed that members of the communities perceived these online platforms as great places to experience the commonality between them.

\section{The connection between findings and the face-to-face DGEP}

The face-to-face DGEP runs for 10 weeks including various types of activities such as; initial assessment, weekly 1-h personalized exercise session, one-hour interactive group education regarding diabetes-related topics (e.g., diet, mindfulness, foot care, living with a chronic condition, etc.), and a final assessment at the end of the program. Previous participants have made positive changes and improvement in their diabetes health [35]. One of the most important objectives of this program is to keep patients connected to the program after discharge. In this regard, our findings show the connection between identified themes and the objectives of the program. As can be seen in the following table, there are overlaps between identified themes and activities in each phase during the face-to-face diabetes group education program. For example, findings of theme one occurring in the "during the program" and "after discharge" phase in the faceto-face diabetes group education program. In which, patients can benefit OHCs to exchange advice, experiences, and resources with others (Table 2).

Because of the nature of the DGEP, patients need to be in a waiting list to join the program due to the high demands. As new patients need to participate in some questionnaires such as PAID (Problem Area in Diabetes

Table 2 The connection between findings and the program

\begin{tabular}{|c|c|c|c|c|}
\hline \multirow[t]{2}{*}{ Theme } & \multirow[t]{2}{*}{ Value extension of the DGEP } & \multicolumn{3}{|l|}{ Phase } \\
\hline & & Prior to join & $\begin{array}{l}\text { During the pro- } \\
\text { gram }\end{array}$ & $\begin{array}{l}\text { After } \\
\text { dis- } \\
\text { charge }\end{array}$ \\
\hline 1 & $\begin{array}{l}\text { - 24/7 information and experience sharing } \\
\text { - Online resource sharing (e.g., article, video, weblogs, ...) } \\
\text { - Exchange lifestyle-related advice }\end{array}$ & & $\checkmark$ & $\checkmark$ \\
\hline 2 & $\begin{array}{l}\text { - Increase patient's readiness } \\
\text { - Better communicate with the HCPs } \\
\text { - Encourage peers } 24 / 7 \text { to keep on track }\end{array}$ & $\checkmark$ & & $\checkmark$ \\
\hline 3 & $\begin{array}{l}\text { - Improve emotional wellbeing by experiencing commonality } \\
\text { - Reduce the stress of patients }\end{array}$ & & $\checkmark$ & $\checkmark$ \\
\hline
\end{tabular}


scale) and diet questionnaires before joining to the program, OHCs provide ideal environments for them to actively engage in online resource sharing and communicating with healthcare team and discharged patients. The outcome of this process is enhanced patient capabilities, helping them further understand the benefits of participating in the program and increase their readiness prior to join to the program. In addition, the outcome will support carers with daily load, making them feel they have more support.

During 10-week DGEP, patients have opportunities to meet others with the same problems, which leads them to feel they are not alone. Moreover, community encouragement (theme 2) occurs during the program when patients participate in group-based activities such as exercise and educational sessions. According to our observation, during the program, patients provided with 1-h educational sessions to improve their diabetes health literacy and discuss their challenges. Patients encourage each other to achieve their health-related goals, share advice and brainstorm solutions (theme 3) during the program. After discharge from the program, patients need to self-manage their diabetes and stick to their health plan, as there is no diabetes cure. The proposed framework enables them to keep connected to the program, which was a challenging issue for the face-to-face DGEP. Across all stages, we identified value co-creation behaviors such as resource integration, informants' sharing, social and emotional support. Our findings illustrate that patient participation in diabetes online health communities leads to co-created value. Similarly, participants in the 10-week DGEP improved their psychological wellbeing and self-care (see Appendix 1). Since our findings align with the interactional creation framework [27], which focuses on value co-creation through interactions and customer-dominant logic and how providers participate, at a profit, in customers' value formation [30], we applied interactional co-creation framework in all phases of this study to conceptualize diabetic patients online behavior and investigate the practices and outcomes. The proposed information-sharing framework focused on patients as active members for online value co-creation. The proposed framework in this study is innovative because none of the research over the past address this educational delivery through online value co-creation for empowering patients in self-management of their diabetes. Patients are treated as the most significant stakeholders in our framework, representing their human information behavior. Diabetic patients participate and experience different types of value co-creation through social support and emotional support exchange.

Our findings that were used to develop the proposed framework are meaningful in practice. Applying our novel framework in the healthcare domain especially, chronic diseases such as type-2 diabetes would assist healthcare organizations in delivering appropriate health services and improve health outcomes. The proposed framework is flexible and can be tailored to special diabetes-related educational program, as the quality of care and self-management of chronic diseases will become a more significant issue. Our research further provides recommendations to the healthcare industry on how to effectively contribute to the online intervention as previous research contended that healthcare organizations perceived $\mathrm{OHCs}$ as a tool for extending the communication from a traditional power balance between HCPs and patients to online interactions amongst all stakeholders. By improving the design and evaluation artefact, we extended the target body of the knowledge in the field of medical informatics and healthcare service delivery sector by enhancing the theory of empowerment in which, patients are the central aspect of the theory and HCPs, and healthcare organizations are facilitators of the value co-creation process in particular for information sharing aspect in order to provide quality lifestyle interventions for human living with diabetes. We do believe that the proposed framework would be a good step toward the implementation and promoting information behavior in meeting the current challenges of diabetes group-based education program (e.g., keep patients connected to the program after discharge). The study is also concerned about the validity of the proposed framework in relation to its value-adding within the healthcare service domain. After the development of the framework, we presented it to three experts (e.g., diabetic's program coordinators in healthcare industries). We captured some feedback, after conducting three expert interviewing sessions as mentioned earlier. The outcome concerning the validity of the framework can be viewed in Appendix 2. The reflective feedback indicated a positive sense towards the feasibility of the proposed framework for effective information sharing behavior illustrating potential changes. Our findings contend that people with diabetes are willing to use OHCs to find information and support about their diabetes. Participating in OHCs empowers diabetes patients in the self-management process through the exchange of health information and experiences.

\section{Conclusions}

This study proposed a novel OHC framework for a DGEP to shed lights on the role of digital health platforms in the field of medical informatics. The framework focused on the health journey of people with type-2 diabetes ranging from pre-joining to the DGEP to discharge from the program. We do believe that the framework proposed in this study offers significant potential in addressing the growing need for efficient and effective type- 2 diabetes self-management. 
On a broader clinical and research scale, this framework can apply to developing fully functional $\mathrm{OHC}$ or mobile app for people with type- 2 diabetes. Patients and healthcare professional team would benefit from the remote accessibility, and group-based online activities and resource sharing. The findings highlight the importance of patient participation in diabetes education programs, particularly in relation to self-management. Patient participation in diabetes online communities leads to patient-reported improvements in psychological and emotional well-being. Our findings contribute to both theory and practice. Our framework provides a tool for healthcare organizations to realize the potential for patient engagement and the promotion of effective self-care offered by OHCs through online value co-creation. In terms of practical implications, we translated empowerment theory into practice by proposing a novel framework for OHCs to engage all stakeholders before they join, during, and after the face-to-face program.

\section{Partnering for Patients with Diabetes}
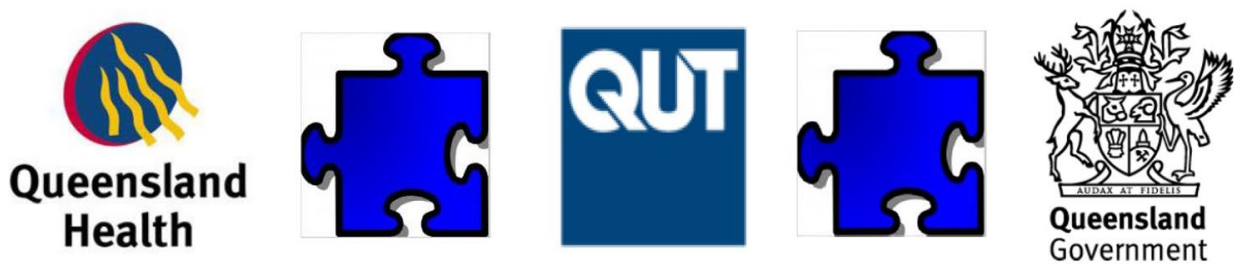

Andrea Cawte

QUT Health Clinics Nutrition \& Dietetic Clinic Co-Ordinator

RBWH Diabetes Dietitian

Diabetes Educator

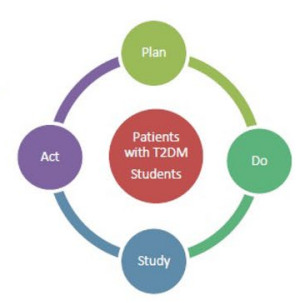

\section{Partnership - RBWH \& QUT}

\section{Better outcomes for patients}

- Increase access to appropriate care

- Reduce RBWH diabetes wait list

- Improve clinical outcomes

- Improve patient experience

2. Inter-disciplinary student clinical experience

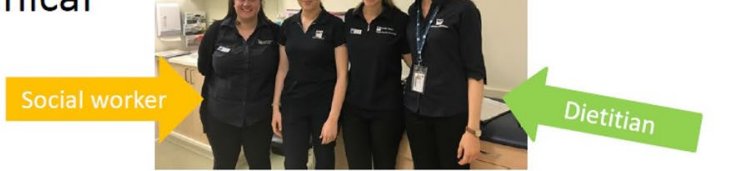




\section{Evidence}

NHMRC 'National Evidence Based Guidelines for Patient Education in T2DM' (2009)

- All patients with T2DM should be referred for diabetes education (Grade A)

- Education should be structured, interactive and delivered in either groups or individually (Grade A) Caligari R, Girgis S, Eigenmann C, Gomez M, Griffiths R. National Evidenced Based Guideline for Patient Education in Type 2 Diabetes. Diabetes Australia and the NHMRC, Canberra 2009

ADA "Standards of Medical Care in Diabetes' (2017) $\underline{11}$

- All patients receive diabetes self-management education (Grade B)

- Lifestyle education, include nutrition therapy and physical activity (Grade B)

- All patients should have an annual foot and eye examination (Grade B)

Standards of medical care in diabetes-2016: Summary of revisions. (2016). Diabetes Care, 39 Suppl 1(Supplement 1), S4-S5. doi:10.2337/dc16-5003

Group based diabetes self-management education compared to routine treatment for people with type 2 diabetes mellitus. A systematic review with meta-analysis.

\section{The Program}

- 2016 - Pilot

- 2017 - 3 groups

- 2018 - 4 groups

- 2019 - 5 groups planned

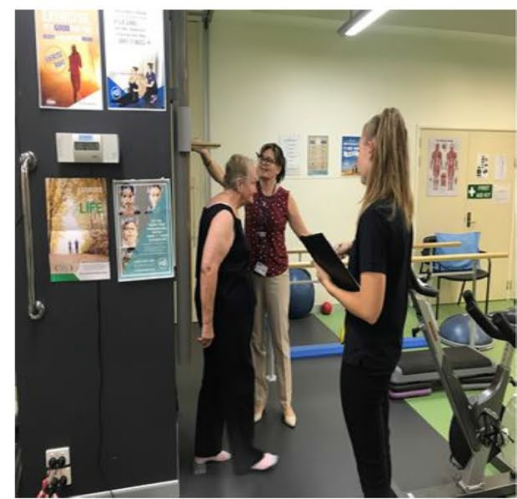

\section{What is The Program ?}

- Initial assessment

- Eight weeks of exercise (1 hour) + education (1 hour)

- Final assessment

- Individual optometry appointment

- Individual podiatry appointment in highrisk foot clinic

- Monthly follow-up program - RECHARGE

- Case conference for handover of patient care

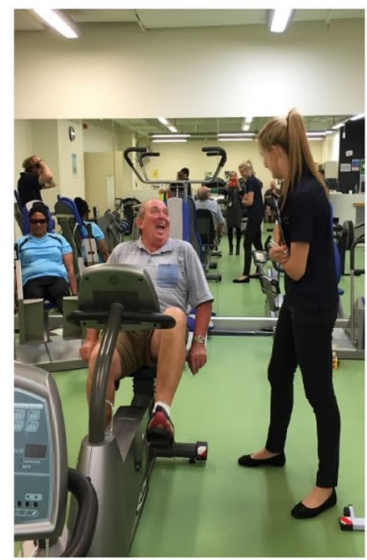




\section{What is The Program ?}

- Initial assessment - interdisciplinary team

- Weight, waist circumference, height, BMI

- Relevant data collection

- MHx, medications, lifestyle factors,

- SBGM

- Exercise tolerance testing

- BGLs, BP pre \& post exercise

- Diet fat \& fibre questionnaire

- PAID

- Pathology - HbA1c, cholesterol profile, urinary albumin, fasting glucose

- Social worker screening

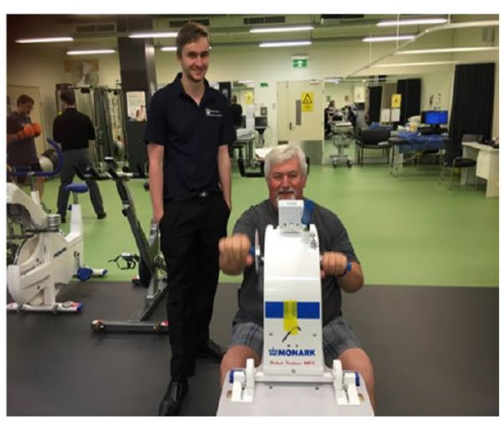

\section{What is The Program ?}

-What do the eight weeks contain?

- One hour exercise followed by one hour education

- Individualised exercise program prescribed by exercise physiology student and approved by exercise physiologist AEP (based on results from initial ax)

- Weekly pre \& post exercise screening

- Weekly exercise one-on-one supervision with exercise physiology student for hour program

- Weekly exercise goals negotiated by exercise physiology student based on patient performance, barriers, motivators

- Weekly nutrition goals negotiated by dietitian student from patient diet history

- Home program provided by exercise physiology student

- Updates to gym program and/or home program and/or goals as required 


\section{What is The Program ?}

- What do the eight weeks contain?

- One hour exercise followed by one hour education

\begin{tabular}{|c|c|c|}
\hline DATE & SESSION & HCP \\
\hline WEEK 1 & What is diabetes? Bodylink & $\begin{array}{l}\text { Credentialled Diabetes } \\
\text { Educator }\end{array}$ \\
\hline WEEK 2 & Goal setting \& motivation & Psychologist \\
\hline WEEK 3 & Food \& nutrition 1 & Dietitian \\
\hline WEEK 4 & Diabetes Complications & $\begin{array}{l}\text { Credentialled Diabetes } \\
\text { Educator }\end{array}$ \\
\hline WEEK 5 & Food \& nutrition 2 & Dietitian \\
\hline WEEK 6 & Foot \& eye health & Podiatrist \& Optometrist \\
\hline WEEK 7 & Mindfulness \& non-hungry eating & Psychologist \& Dietitian \\
\hline WEEK 8 & Medications \& Where to from here & $\begin{array}{l}\text { Credentialled Diabetes } \\
\text { educator \& care } \\
\text { coordinator }\end{array}$ \\
\hline
\end{tabular}

\section{What is The Program ?}

- Final assessment - interdisciplinary team changes to:

- Weight, waist circumference, height, BMI

- Relevant data collection

- MHx, medications, lifestyle factors, SBGM

- Exercise tolerance testing

- BGLs, BP pre \& post exercise

- Diet fat \& fibre questionnaire

- PAID

- Pathology - HbA1c, cholesterol profile, urinary albumin, fasting glucose

- Social worker ongoing support

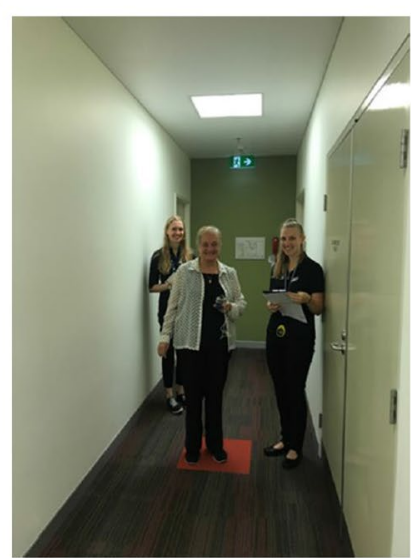




\section{How good is The Program ?}

- Attendance

\begin{tabular}{|ll|l|l|l|}
\hline N=73 & & $\begin{array}{l}\text { Commenced } \\
\text { Program }\end{array}$ & $\begin{array}{l}\text { Completed >7/8 } \\
\text { exercise + education }\end{array}$ & Complete Final Ax \\
\hline Group Pilot & 2016 & 10 & $80 \%$ & 9 \\
\hline Group 1 & 2017 & 8 & $88 \%$ & 8 \\
\hline Group 2 & 2017 & 12 & $83 \%$ & 11 \\
\hline Group 3 & 2017 & 8 & $88 \%$ & 8 \\
\hline Group 1 & 2018 & 11 & $64 \%$ & 8 \\
\hline Group 2 & 2018 & 12 & $58 \%$ & 9 \\
\hline Group 3 & 2018 & 12 & $83 \%$ & 10 \\
\hline Group 4 & 2018 & $1 *^{*}$ not included in below total & Program ongoing & Program ongoing \\
\hline Total & & 73 & $78 \%$ & 63 (86\%) \\
\hline
\end{tabular}

\section{How good is The Program ?}

\begin{tabular}{|c|c|c|c|}
\hline Outcome Measure & $\mathrm{n}$ & $\%$ improved & Change \\
\hline Weight & 49 & 69.4 & $-1.2 \mathrm{~kg}$ \\
\hline Waist Circumference & 49 & 71.4 & $-1.83 \mathrm{~cm}$ \\
\hline $\mathrm{HbA1c}$ & 43 & 74.4 & $-0.4 \%$ \\
\hline Fasting BGL & 33 & 63.6 & $-0.86 \mathrm{mmol} / \mathrm{L}$ \\
\hline Diet Score (Total) & 49 & 81.6 & +0.3 score \\
\hline PAID & 41 & 80.5 & -16.25 score \\
\hline 6 Minute Walk Test & 33 & 69.0 & $+26 \mathrm{~m}$ \\
\hline Satisfaction (SAPS) & 49 & \multicolumn{2}{|c|}{$90 \%$ satisfied or very satisfied } \\
\hline
\end{tabular}




\title{
How good is The Program?
}

- Satisfaction

- Patient quotes

- "I found this course informative and encouraging...I would recommend this course and its staff to anybody...it has definitely set me up with strategies I need to achieve my goals."

- "..feel more confident about direction of my disease, less fatalistic, happier.."

- "..group environment was special...my GP was very impressed and has many more patients she can send.. All staff were excellent, professional and approachable."

- QUT students \& staff quotes

- "..good opportunity to observe other allied health members." "..represents effective inter-professional learning, multidisciplinary care and improved partnership with QUT and RBWH."

\section{Acknowledgements:}

\author{
Jane Musial: Senior Dietitian RBWH \\ Heike Krausse: Credentialed Diabetes Educator RBWH \\ Robert Mullins: Senior Lecturer, Director of Clinical Services and Education, School of Exercise and Nutrition \\ Sciences, Faculty of Health, QUT \\ Mary Hannan-Jones: Director of Academic Programs, Senior Lecturer, School of Exercise and Nutrition Sciences, \\ Faculty of Health, QUT \\ Lisa Morgan: QUT Health Clinics Manager \\ QUT Health Clinic Coordinators - Andrew McWilliams, Vanessa Spiller, Elizabeth Madden, Tina Huynh, Alex Skinner \\ QUT administration staff \\ Dr Michael D'Emden: Director Endocrinology RBWH \\ Lisa Dieckmann: AO Diabetes RBWH \\ Dr Adrienne Young: Research Co-ordinator Dept Nut \&Diet RBWH \\ Dr Susan De Jersey: Research Co-ordinator Dept Nut \&Diet RBWH \\ Wing Yan Leung (Bonnie): Past Student Dietitian QUT \\ Chelsea Allport: Student Dietitian QUT
}




\section{Appendix 2}

The evaluation of confirmatory expert interviews on the usability and efficiency.

\begin{tabular}{ll}
\hline Validity assessment & Outcomes \\
questions & HCP's comments \\
& port; N=No, I sup- \\
don't support; \\
N/A = Not \\
applicable) \\
(HCPs)
\end{tabular}

Useful diabetes-related $\quad Y \quad Y \quad Y \quad$ HCP 1:"24/7 service can be health information can very useful for patient who be accessed and shared missed the face-to-face among patients $24 / 7 \quad$ program. They may share information anytime" (not only limited to the program hours) their diabetes-related stories with others"

HCP 3: "patients can cut-off their time regarding seeking for health information on online platforms"

The framework can keep $\quad Y \quad$ Y $\quad Y \quad$ HCP 1: "We can provide Repatients connected charge program (monthly to the program after follow-up) online!" discharge (phase 3)

\section{The framework assists patients who are in a waiting list to decrease their stress before joining the program \\ The framework can improve the self-man- agement skills of patients to cope with daily chal- lenges concerning their diabetes}

\section{HCP 1: "They can easily find useful information about the program and seek advice from discharge patients" \\ HCP 3: "The framework improve their health literacy about type-2 diabetes"} help for follow-up program"

HCP 2: "Dietary advice by HCPS can be available anytime for patients to make sure that they stick to the plan" HCP 3: "System is useful and

N/A Y Y HCP 2: "The framework assists patients support each other action"

HCP 3: "The shared-information might enhance patients self-management skills and help them manage their daily challenges"

The framework is useful for $Y \quad Y \quad$ N/A HCP 1:"I note that the healthcare organizations to add value to the current face-to-face DGEP each phase but that the A, $P$, and $P^{\prime}$, and I are different in
HCP 2: "They can easily share and put their skills into

Newcastle City Campus, Newcastle, Australia. ${ }^{3}$ Faculty of Health, Queensland University of Technology (QUT), Brisbane, Australia.

Received: 14 December 2020 Accepted: 24 June 2021

Published online: 7 July 2021

\section{References}

1. Brown LK, Veinot TC. Information behavior and social control: toward an understanding of conflictual information behavior in families managing chronic illness. J Assoc Inf Sci Technol. 2020. https://doi.org/10.1002/asi. 24362.

2. Roglic G. WHO Global report on diabetes: a summary. Int J Noncommun Dis. 2016;1(1):3.

3. Ogurtsova K, da Rocha Fernandes J, Huang Y, Linnenkamp U, Guariguata L, Cho NH, Cavan D, Shaw J, Makaroff L. IDF Diabetes Atlas: global estimates for the prevalence of diabetes for 2015 and 2040. Diabetes Res Clin Pract. 2017;128:40-50.

4. Funnell MM, Anderson RM. Empowerment and self-management of diabetes. Clin Diabetes. 2004;22(3):123-7.

5. Costello KL. Impact of patient-provider communication on online health information behaviors in chronic illness. Proc Assoc Inf Sci Technol. 2016;53(1):1-10.

6. Aghdam AR, Watson J, Cliff C, Miah SJ. Improving the theoretical understanding toward patient-driven health care innovation through online value cocreation: systematic review. J Med Internet Res. 2020;22(4):e16324.

7. Van Oerle S, Lievens A, Mahr D. Value co-creation in online healthcare communities: the impact of patients' reference frames on cure and care. Psychol Mark. 2018;35(9):629-39.

8. Yan Z, Wang T, Chen Y, Zhang H. Knowledge sharing in online health communities: a social exchange theory perspective. Inf Manag. 2016;53(5):643-53.

9. Liu QB, Liu X, Guo X. The effects of participating in a physician-driven online health community in managing chronic disease: evidence from two natural experiments. MIS Q. 2020. https://doi.org/10.25300/MISQ/ 2020/15102.

10. Lange K. Förderung der eigenverantwortlichen Therapie bei Typ-2-Diabetes. Diabetologe. 2006;2(6):484-92.

11. Su D, Michaud TL, Estabrooks P, Schwab RJ, Eiland LA, Hansen G, DeVany M, Zhang D, Li Y, Pagán JA. Diabetes management through remote patient monitoring: the importance of patient activation and engagement with the technology. Telemed e-Health. 2019;25(10):952-9.

12. Aghdam AR, Watson J, Ziaimatin H. Online value co-creation in the healthcare service ecosystem: a review. In: Proceedings of the 29th Australasian conference on information systems. Australasian Conference on information systems, Australia, 3-5 Dec 2018.

13. Buhlmann M, Merkel W, Wessels B. The Quality of Democracy: Democracy Barometer for Established Democracies, Hertie School of Governance, Working papers, No. 22, April, 2008. https://opus4.kobv.de/opus4-hsog/ frontdoor/deliver/index/docld/80/file/520_hsog_wp_no._22.pdf. Accessed 6 June 2021.

14. Litchman ML, Edelman LS. Perceptions of the diabetes online community's credibility, social capital, and help and harm: cross-sectional comparison between baby boomers and younger adults. JMIR Aging. 2019;2(2):e10857. each phase and this bit I can understand!"

HCP 2: "healthcare organizations leverage digital health platforms as a new approach to coordinated patient care"

\section{Author details}

'School of Information Systems, Queensland University of Technology (QUT), Brisbane, Australia. ${ }^{2}$ Newcastle Business School, The University of Newcastle,
15. Osei-Frimpong K, Wilson A, Owusu-Frimpong N. Service experiences and Serv Theory Pract. 2015;25(4):443-62.

16. McColl-Kennedy JR, Vargo SL, Dagger TS, Sweeney JC, Kasteren YV. Health care customer value cocreation practice styles. J Serv Res. 2012;15(4):370-89.

17. AlMarshedi A, Wills GB, Ranchhod A. The Wheel of Sukr: a framework for gamifying diabetes self-management in Saudi Arabia. Procedia Comput Sci. 2015;63:475-80.

18. Fisher L, Polonsky W, Hessler D, Potter M. A practical framework for encouraging and supporting positive behaviour change in diabetes. Diabet Med. 2017;34(12):1658-66. dyadic value co-creation in healthcare service delivery: a CIT approach. J 
19. Findlay-White F, Slevin M, Carey ME, Coates V."What's the Point?": understanding why people with type 2 diabetes decline structured education. Clin Diabetes. 2020;38(2):166-75.

20. Odgers-Jewell K, Ball L, Kelly J, Isenring E, Reidlinger D, Thomas R. Effectiveness of group-based self-management education for individuals with Type 2 diabetes: a systematic review with meta-analyses and metaregression. Diabet Med. 2017;34(8):1027-39.

21. Sim K-H, Kim S-y, Lee M-K, Lee M-S, Kim K-W. P-178 Effect of Diabetes Self-Management Education (DSME) on glycemic control in patients with Type 2 diabetes. Diabetes Res Clin Pract. 2008;79:120.

22. Funnell MM, Tang TS, Anderson RM. From DSME to DSMS: developing empowerment-based diabetes self-management support. Diabetes Spectr. 2007;20(4):221-6.

23. Heisler M. Different models to mobilize peer support to improve diabetes self-management and clinical outcomes: evidence, logistics, evaluation considerations and needs for future research. Fam Pract. 2010;27(Suppl_1):i23-32.

24. Zimmerman MA. Empowerment theory. In: Handbook of community psychology. New York: Springer; 2000. pp. 43-63.

25. Ellis SE, Speroff T, Dittus RS, Brown A, Pichert JW, Elasy TA. Diabetes patient education: a meta-analysis and meta-regression. Patient Educ Couns. 2004;52(1):97-105.

26. Mensing CR, Norris SL. Group education in diabetes: effectiveness and implementation. Diabetes Spectr. 2003;16(2):96-103.

27. Ramaswamy V, Ozcan K. What is co-creation? An interactional creation framework and its implications for value creation. J Bus Res. 2018;84:196-205.
28. Steinsbekk A, Rygg L, Lisulo M, Rise MB, Fretheim A. Group based diabetes self-management education compared to routine treatment for people with type 2 diabetes mellitus. A systematic review with metaanalysis. BMC Health Serv Res. 2012;12(1):213.

29. Duggan $M$, Smith A. $6 \%$ of online adults are Reddit users. Pew Internet Am Life Proj. 2013;3:1-10.

30. Heinonen K, Strandvik T. Customer-dominant logic: foundations and implications. J Serv Mark. 2015. https://doi.org/10.1108/ JSM-02-2015-0096.

31. Braun V, Clarke V. Using thematic analysis in psychology. Qual Res Psychol. 2006;3(2):77-101.

32. Palumbo R, Annarumma C, Musella M. Exploring the meaningfulness of healthcare organizations: a multiple case study. Int J Public Sect Manag. 2017;30(5):503-18.

33. Beirão G, Patrício L, Fisk RP. Value cocreation in service ecosystems: investigating health care at the micro, meso, and macro levels. J Serv Manag. 2017;28(2):227-49.

34. Schram MT, Baan CA, Pouwer F. Depression and quality of life in patients with diabetes: a systematic review from the European Depression in Diabetes (EDID) Research Consortium. Curr Diabetes Rev. 2009;5(2):112-9.

35. Clinic Q. QUT- DGEP Queensland Health. https://metronorth.health.qld. gov.au/news/diabetes-management-north-lakes. Accessed 25 June 2020.

Publisher's Note Springer Nature remains neutral with regard to jurisdictional claims in published maps and institutional affiliations. 